\title{
Monitoring And Evaluation And Sustainability Of Mwisoko Project, Rwanda
}

\author{
Fauzia CHINA ${ }^{1}$, Dr Mercyline Kamande ${ }^{2}$ \\ ${ }^{1}$ School of Business and Economics, Mount Kenya University, \\ Kigali, Rwanda \\ ${ }^{2}$ School of Business and Economics, Mount Kenya University, \\ Kigali, Rwanda
}

DOI: 10.29322/IJSRP.11.10.2021.p11879

http://dx.doi.org/10.29322/IJSRP.11.10.2021.p11879

\begin{abstract}
The study examined the contribution of monitoring and evaluation on sustainability of Mwisoko project in Rwanda. Specifically, this research ascertains effect of monitoring and evaluation planning, process, and tools on sustainability of Mwisoko project in Nyarugenge District. A descriptive and correlation research designs were used. The target population comprised of 345 (three key employees of Mwisoko project, two employees of Kigali City, one employee of Nyarugenge district, and 340 business enterprises beneficiaries of the project).Quantitative data was gathered using questionnaire survey while qualitative data was obtained using interview guide. A descriptive and inferential statistics were used to analyze quantitative information. Information obtained from secondary source was analyzed using content analysis. A multiple regression model was adopted to test correlation between variables. Results indicated that monitoring and evaluation planning was positively correlated with sustainability of Mwisoko project $(\mathrm{b}=0.168, \mathrm{p}=0.002)$. Monitoring and evaluation process was positively significant to the sustainability of Mwisoko project $(b=0.257, p$ value $=0.000)$. Monitoring and evaluation tools is strongly related to sustainability of Mwisoko project $(b=0.372, p-$ value $=0.000$ ). The study recommends that Mwisoko project stakeholders should hire external experts to do M\&E Planning related to project for enhancing the sustainability of projects. Beneficiaries should participate in design, planning and conception of monitoring and evaluation process for increasing the success of project in City of Kigali. There is a need to plan an adequate design for different tasks and estimate the total cost, means to plan according to the budget as well as empower the management of Mwisoko project.
\end{abstract}

Keywords: Monitoring, Evaluation, Planning, Process, Project, Tool. Sustainability.

\section{Introduction}

Although, monitoring and evaluation plays a significant role to project sustainability, in Rwanda, most of project are failing such as four storey building in Nyagatare (Michael \& Eleanor,2011), multi-storey block at the University of Rwanda, (Government of Rwanda, 2013) and, women holtcullutre project in Rulindo Distrcit (Kule \&Umugwaneza,2016). NGO are encountering with several constraints, more than inability to respond to challenging needs. Previous studies estimate that about $33 \%$ of the project is at risk of failure (Banyenzaki, 2015). In fact, being low rate of earned income (Basha, 2017), failure of project started earlier and inactive existence (Gaitano, 2011), discontinue of financial support after the grand has end (Cusworth \& Franks, 2013), discontinue to reach additional beneficiaries (Gilbert \& Ron, 2014) are indicators of unsustainable projects. Project Monitoring \& Evaluation in Rwanda is not strong owing to poor planning, inadequate tools and methods, and poor budgeting.

SMEs Project in the Kigali City fail to attain their objectives as encapsulated in the City financial report in the last five years(2016-2019) out of 2750 project, only $29 \%$ were sustainable in 2016, 33\% in 2017, 49\% in 2018 and 51\%b in 2019(City of Kigali, 2020). In search of way to improve sustainability of projects, it is generally contended that M\&E system can play a significant role (Shah, 2013). Appropriate M\&E process (Acevedo, 2010), M\&E tools (Chesos, 2010), and in the recommendations of Mackay (2010) emphasized on the need M\&E budget achieving project sustainability. All the above elements were strategies used to enhance project sustainability. Nyarugenge District recorded a rate of project failure for SMEs financial by Mwisoko Project (MINECOFIN, 2013). However, empirical evidence on the extent to which monitoring process, tools and budget have contributed to project failures and by extension project sustainability is lacking and this is the gap this research intended to fill. This consideration led the researcher to the research problem consisting in knowing if and how monitoring and evaluation contribute to the sustainability of Mwisoko Project in Nyarugenge Distrcit, Rwanda.

The research objectives were:

From above general and specific objectives are the following:

(i)To ascertain effects of monitoring and evaluation planning on sustainability of Mwisoko project in Nyarugenge District.

This publication is licensed under Creative Commons Attribution CC BY.

http://dx.doi.org/10.29322/IJSRP.11.10.2021.p11879

WWW.ijsrp.org 
(ii)To analyze effects of monitoring and evaluation process on sustainability of Mwisoko project in Nyarugenge District.

(iii)To explore effects of monitoring and evaluation tools on sustainability of Mwisoko project in Nyarugenge District.

\section{Review of Literature}

The review of existing studies according to the study specific research objectives that are: to analyze effects of monitoring and evaluation process on sustainability of Mwisoko project in Nyarugenge District, to assess effect of monitoring and evaluation tools on sustainability of Mwisoko project in Nyarugenge District and to ascertain effects of monitoring and evaluation planning on sustainability of Mwisoko project in Nyarugenge District.

A study conducted on eleven developing economies demonstrated a clear fragmented model to plan relying on technical and systematical problems on expenses of policies and other organizational concerns (Center for Learning on Evaluation \& Results [CLEAR], 2013). In this case, adequate and suitable management is affected by inappropriate follow up operations undertaken to enhance practices and disseminating information (Khan, 2010). This is very important in increasing project performance and continuity. M\&E systems would be constantly followed up, usually revised and ameliorated.

Asaka, et, al.(2012) in their surveys on ameliorating the continuity of any program after termination of donor funds, assessment of local community involvement as probable options, undertaken in Malawi, countries that local level would participate in developmental projects that was under their management. This study recommends more studies to investigate the influence of local level planning. When $M \& E$ is assumed adequately and clearly, it would stimulate to have sustainable projects and ameliorate future project plan (Florin, 2011).

Ika, et al.(2010) argued that monitoring and evaluation necessitates to operate as an integral system of sustainability for small and medium enterprises business. To correctly assess them to manage project and assessment would be ongoing activities. It went usually with follow up, consideration of data given via systematic evaluation, researches and revise facts and took into consideration project targets. Therefore, they are very important to test project. Therefore, this necessitates to be implemented untimely relying on objectives. The evaluation is important in post project execution for identifying new and medium effect of project. This research varies from the present one in that the research was carried out not in Rwanda, therefore, contextual gap.

Shimwa (2019) studied the impact of project on implementation practices on sustainability of electricity access rollout project (EARP) in Nyarugenge District, Rwanda. The study adopted a descriptive and correlation research designs on a small sample size. The study revealed a positive and clear link between M\&E implementation and sustainability of EARP. However, the research did not really take into consideration, the influence of M\&E process in enhancing the project sustainability.

M\&E planning system of SMEs and development project have combined different models that jointly selective, log frame, results based and survey, approval, participative, effects assessments, cost benefits analysis (World Bank, 2015).Cusworth and Franks (2013) reiterated that Saudi Arabia did not possess adequate building contract success estimation, determination and examination requirements and sub-requirements for a choice outline. Absence of evaluation is negatively correlated with performance. A study of Mladenovic, et al. (2013) found out that twofold model for measuring the cooperation between governmental and nongovernmental organizations. Firstly, it has been relied on evaluation of expected targets from the starting point of every beneficiaries meaning, profit rate, adequacy and worth for governmental institutions and degree of service provision.

Furthermore, balanced scorecard is the second one that is used to evaluate project implementation relied on various point of view that has been in finance, client, internal business procedures, learning and development. In addition, Alhyari et al. (2013) evidenced that the above model fixed much on follow up and calculating the success of electronic-government success of electronic public and in assessing in IT program reserves.

The logical framework refers to the pertinent model adopted in managing project for designing and follow up. Its table denotes the adoptable for all projects involved in community developmental operations (Martinez, 2011). A study of Hummelbrunner (2010) argues that perpetual utilization of logical framework in spite of various blames. The author specifies that this system diminishes such disagreements. Notwithstanding with most of funders recognize its constraints and threats, they preserve its utilization. According to Myrick (2013) argues that a practical model to monitoring and evaluation is accurate and can be restricted by challenges that would prohibit their perpetual utilization of a logical framework and practical model. Logical framework is very important in gathering information, copy and presenting information.

Moreover, additional models are for instance stochastic, fuzzy, and miscellaneous. These methods are very important, accurate, flexible and adaptable for wide programs (Abdul \& Muhammad, 2011). Numutesi (2018) carried out a master research project at Mount Kenya University Rwanda on effects of M\&E on pproject performance using Africa indoor residual spraying (AIRS). The study used inferential statistics on a small sample size. The study revealed the findings on the extent to which public reporting affects the organizational performance, the role of feedback on performance and relationship between change documentation and organizational performance. However, this study did not really take into consideration, the effects of $\mathrm{M}^{\wedge} \mathrm{E}$ tools in enhancing project sustainability.

The below diagram indicates that there is a relationship between M\&E, project sustainability and ethics in M\&E. The effects of $\mathrm{M} \& \mathrm{E}$ were pertinent in stimulating the achievement of project measurements. The project sustainability was impacted by M\&E. 


\section{Independent variable}

Project Monitoring and evaluation
Dependent variable

Sustainability of Mwisoko Project

Monitoring and evaluation planning

- Indicators formulation

- $\quad$ Setting agreed targets

- Strategies to address problems

- Data collection plan

\section{Monitoring and Evaluation Process}

- Baseline monitoring

- Impact monitoring

- Impact evaluation

- The focus on efficiency and execution

\section{- Monitoring and Evaluation Tools}

- Logical Framework

- Rapid appraisal methods

- Participatory methods

- Cost effectiveness

- Effective analvsis

\section{Mloderating variable}

- Income Generating Activities

- Sustainable auto finance

- Continuity benefit to reach others

- $\quad$ Ethics in M\&E

\section{Moderating Variables}

\section{Figure 2. 1 Conceptual Framework}

According to figure 2.1, monitoring \& evaluation and project sustainability are interrelated. Monitoring and evaluation cannot enhance project sustainability if it is not carried out effectively and efficiently. In this regards, monitoring and evaluation process can to a great extent enhance project sustainability. It decrease the gap between the actual and expected. Further M\&E tools or approaches if not adequately adopted in project monitoring, pertinent actions were questionnaire to practices the profit occurring.

M\&E Planning may increase project sustainability. It was measured using timeline, cost, scope and quality of service rendered. $M \& E$ practices were unable to improve sustainability if not conducted professionally and competently. Ethics in M\&E is very pertinent in project sustainability.

\section{Materials and Methods}

A research design refers to the process of preparing conditions in collecting but also analyzing information for putting together pertinent to the study aim with economy during a research process (Mauro, \& Marly, 2014). The research design is made of the 
outline techniques on data collection, measuring and data analysis. The current research applied a descriptive research design comprising a mixed approach for gathering and analyzing information.

In this regards, the population under this research involves Mwisoko project staff ( 3 staff), The City of Kigali ( 2 staff) and one district's (Nyarugenge district) SMEs beneficiaries of Mwisoko project grouped in 6 cooperatives of 340 members in total making a targeted population 345 people. The sample size is obtained by using Yamane formula. In this regards. The sample size was calculated by the following formula.

$\operatorname{Eq}(1):$

$n=\frac{N}{1+N(e)^{2}}$

When

The study sample size of 186 respondents that participated in the research process of the present study. A simple random sampling technique was used. Methods of collecting information under the present study were basically the use of questionnaire and interview. Information was analyzed descriptively by demonstrating means and standard deviation. In addition, inferential statistics were applied to establish a correlation and regression analysis, between variable.

4. Results and Discussion

4.1. Effect of Monitoring and Evaluation Planning on Sustainability of Mwisoko Project in Nyarugenge District. Correlation Analysis

\begin{tabular}{|c|c|c|c|c|c|}
\hline & & $\begin{array}{l}\text { Increased Earned } \\
\text { Income Targets }\end{array}$ & $\begin{array}{l}\text { Project Started } \\
\text { Earlier and active } \\
\text { Exist }\end{array}$ & $\begin{array}{l}\text { Sustainable } \\
\text { Auto-Finance }\end{array}$ & $\begin{array}{l}\text { Continuity to } \\
\text { Reach Others }\end{array}$ \\
\hline \multirow[t]{3}{*}{ M\&E Planning } & $\begin{array}{l}\text { Pearson } \\
\text { Correlation }\end{array}$ & $.158^{*}$ & $.413^{*}$ & $.710^{*}$ & $.698 *$ \\
\hline & Sig.(2-tailed) & .015 & .037 & .024 & .034 \\
\hline & $\mathrm{N}$ & 186 & 186 & 186 & 186 \\
\hline
\end{tabular}

\section{Source: Primary Data}

There was positive correlation between monitoring and evaluation planning and increased earned income targets (r.158*, p.015), monitoring and evaluation planning and project started earlier and active exist (r.413*, p.037), monitoring and evaluation planning and sustainable auto-finance (r.714, p.024). The correlations between monitoring and evaluation planning, increased earned income targets, project started earlier and active exist, sustainable auto-Finance and continuity to reach others were statistically significant given that the $\mathrm{p}$ values were $<0.05$ and $<0.01$. The implication was that high levels of monitoring and evaluation planning within Mwisoko project in Nyarugenge District would significantly enhance internal earned income targets, project started earlier and active exist, sustainable auto-finance and continuity to reach others.

Coefficients between Monitoring \& Evaluation Planning, Process, Tools and Sustainability of Mwisoko Project

\begin{tabular}{|c|c|c|c|c|c|c|}
\hline \multirow{2}{*}{\multicolumn{2}{|c|}{$\overline{\text { Model }}$}} & \multirow[t]{2}{*}{$\begin{array}{r}\text { Unstandardized } \\
\text { Coefficients }\end{array}$} & \multicolumn{2}{|c|}{$\begin{array}{r}\text { Standardized } \\
\text { Coefficients }\end{array}$} & & \multirow[t]{2}{*}{ Sig. } \\
\hline & & & Std.Error & Beta & & \\
\hline & \multirow[t]{2}{*}{ (Constant) } & .423 & .162 & & 2.606 & .010 \\
\hline & & & .056 & .168 & 3.082 & .002 \\
\hline 1 & M\&E Planning & .174 & & & & \\
\hline
\end{tabular}

a.Dependent Variable: Sustainability of Mwisoko Project

\section{Source: Primary Data}

The analysis relied on equation used to link dependent and independent variables as follows: Results indicated that M\&E planning was positively and significantly correlated with sustainability of Mwisoko project $(b=0.168, p$-value $=0.002)$. It shows that improvement in M\&E planning stimulate a chance in sustainability of project by 0.168 units.

\subsection{Effect of Monitoring and Evaluation Process on Sustainability of Mwisoko Project in Nyarugenge District}


The second objective analyzed the effect of Monitoring and Evaluation Process on Sustainability of Mwisoko Project in Nyarugenge District. The independent variable (M\&E process) and pproject sustainability) was explored utilizing increased earned income targets, project started earlier and active exist, sustainable auto-finance, continuity to reach others.

Correlation Analysis

\begin{tabular}{|c|c|c|c|c|c|}
\hline & & $\begin{array}{l}\text { Increased Earned } \\
\text { Income Targets }\end{array}$ & $\begin{array}{l}\text { Project Started } \\
\text { Earlier and active } \\
\text { Exist }\end{array}$ & $\begin{array}{l}\text { Sustainable } \\
\text { Auto-Finance } \\
\end{array}$ & $\begin{array}{l}\text { Continuity to } \\
\text { Reach Others }\end{array}$ \\
\hline \multirow[t]{3}{*}{ M\&E Processes } & $\begin{array}{l}\text { Pearson } \\
\text { Correlation }\end{array}$ & $.705^{*}$ & $.530^{*}$ & $.271^{*}$ & .283 \\
\hline & Sig.(2-tailed) & .025 & .041 & .021 & .017 \\
\hline & $\mathrm{N}$ & 186 & 186 & 186 & 186 \\
\hline
\end{tabular}

\section{Source: Primary Data}

There was positive correlation between M\&E processes and earned income targets (r.705*, p.025), monitoring and evaluation planning and project started earlier and active exist (r.530*, p.041), sustainable auto-finance and continuity to reach others (r.271, p.021). The correlations for monitoring and evaluation process and project started earlier and active exist, sustainable autoFinance and continuity to reach others were statistically significant given that the $\mathrm{p}$ values were $<0.05$ and $<0.01$. The implication was that high levels of monitoring and evaluation process within Mwisoko project in Nyarugenge District would significantly enhance internal earned income targets, project started earlier and active exist, sustainable auto-finance and continuity to reach others.

Coefficients between Monitoring \& Evaluation Process, and Sustainability of Mwisoko Project

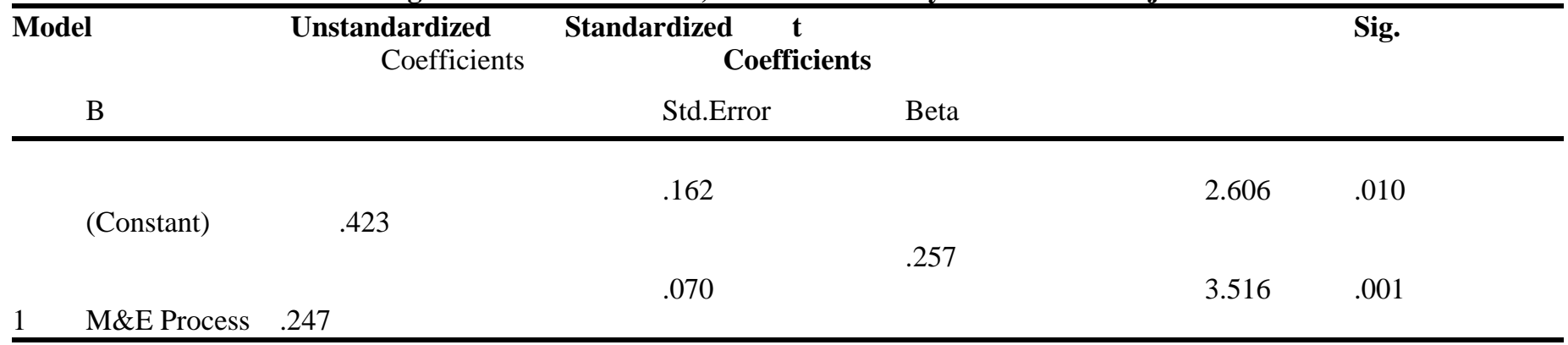

a.Dependent Variable: Sustainability of Mwisoko Project

\section{Source: Primary Data}

The study reiterates that a change in M\&E process stimulates a change in sustainability of Mwisoko project by 0.257 . It means that a change in M\&E process leads to increase of sustainability of Mwisoko project by 0.372 .

\subsection{Effect of Monitoring and Evaluation Tools on Sustainability of Mwisko Project in Nyarugenge District}

The study explores mentoring and evaluation tools used by Mwisoko project in Nyarugenge District. This variable is assessed using logical framework, research based approach, surveys and rapid appraisal methods, participatory methods, impact evaluation, cost benefit and cost effectiveness analysis.

The Pearson correlation was adopted to found effects of M\&E Toola on project sustainability) was explored utilizing increased earned income targets, project started earlier and active exist, sustainable auto-finance, and continuity to reach others.

\section{Correlation Analysis}

\begin{tabular}{|c|c|c|c|c|c|}
\hline & & \multicolumn{3}{|c|}{ Project Started } & \multirow{2}{*}{$\begin{array}{l}\text { Continuity to } \\
\text { Reach Others }\end{array}$} \\
\hline & & $\begin{array}{l}\text { Increased Earned } \\
\text { Income Targets }\end{array}$ & $\begin{array}{c}\text { Earlier and active } \\
\text { Exist }\end{array}$ & $\begin{array}{c}\text { Sustainable } \\
\text { Auto-Finance }\end{array}$ & \\
\hline M\&E Tools & Pearson & $.323^{*}$ & .081 & $.235^{\text {** }}$ & $.707 *$ \\
\hline & Correlation & & & & \\
\hline
\end{tabular}


Sig.(2-tailled)

$\mathrm{N}$
.023

186
.214

186
.001

186
.038

186

\section{Source: Primary Data}

There were correlations between monitoring and evaluation tools and increased earned income targets $\left(r .323^{*}, \mathrm{p} .023\right)$, between monitoring and evaluation tools and sustainable auto-finance (r. 235**, p .001). The correlations between monitoring and evaluation tools and increased earned income targets and sustainable auto-finance were statistically significant given that the $\mathrm{p}$ values were $<0.05$ and $<0.01$. The implication was that high levels of monitoring and evaluation tools within Mwisoko projects would significantly enhance increased earned income targets and sustainable auto-finance. Contrary, the correlations between monitoring and evaluation and project started earlier and active exist was insignificant (r. 081, p .214) as the $\mathrm{p}$ value was > 0.05, and hence the study could not determine how monitoring and evaluation affected project sustainability.

\section{Discussion}

The study findings concur with the observation of Atencio (2012) affirms that the development programs expected to emphasis on problems related and to plan and execution of $\mathrm{M} \& \mathrm{E}$ and the continuity of a project. The study also is relevant compared to empirical study undertaken by Ika, et al. (2010), by arguing that monitoring and evaluation necessitates to operate as an integral system of sustainability for small and medium enterprises projects. To correctly assist manager how to manage and follow up would be ongoing function. This study is relevant to the findings of Cusworth and Franks (2013) who felt that evaluation process is important after project termination to evaluated new and medium project effect.

The study findings coincide with conclusions of Numutesi (2018) who carried out a master research project at Mount Kenya University Rwanda on effects of M\&E on project performance using Africa indoor residual spraying (AIRS). The study revealed the findings on the extent to which public reporting affects organizational performance, the role of Feedback on performance and relationship between change documentation and organizational performance.

The findings from the study were consistent with those by Mbiti and Kiruja (2015) who that M\&E is helpful either to stakeholders or to participants in terms of project advancement assessment. It is beneficial for organization-society relationship, relationship among project personnel and collaboration with partners. It enables the management team to determine stakeholder's effective strategies and possible adjustments that could be adopted. These findings concur with the study conducted on M\&E predominantly mainly considering pertinent determinants of performance, M\& E is among those determinants (Ngogi \& Nyandika, 2014).

\section{Conclusions}

According to results to the first objective, M\&E planning affects clearly sustainability of Mwisoko project in Nyarugenge District. Regardless of this, much effort is needed to plan field visits and undertaking consistent meeting because these are not undertaken as much as possible to guide beneficiaries. Therefore, as well as business skills and entrepreneurs is challenging, there is a need to share information to ensure sustainability of projects undertaken by beneficiaries.

The study demonstrated Monitoring and Evaluation Process contribute more to the sustainability of Mwisoko Project in Nyarugenge District, Rwanda. Through baseline, impact assessment, acceptance of project plan and beneficiaries' involvement, the stakeholder may have accessibility to evidence and data concerning the project in order to reduce the failure and unsustainability of project.

Finally, monitoring and evaluation tools can play a significant role to the sustainability of Mwisoko project in Nyarugenge District. However, special attention was on the lack of consistency and adequacy in using logical framework, research based approach and formal surveys. Therefore, is very important to strengthen the capacity of beneficiaries in order to ensure project sustainability.

Generally, inferential statistics were adopted to establish the correlation between independent variables. Results shows that improvement in monitoring and evaluation planning by one units leads to an increase sustainability of project by 0.168 . The improvement in M\&E makes a change in sustainability of Mwisoko project by 0.257 . The study evidenced that improvement in monitoring and evaluation tools leads to an increase sustainability of Mwisoko project by 0.372 .

The study recommends, Mwisoko project stakeholders should hire external experts to do M\&E Planning related to project for enhancing the sustainability of projects. Beneficiaries should participate actively in designing, planning or conception of M\&E process in increasing project continuity and performance in Kigali, Rwanda. There is a need to plan an adequate design for different tasks and estimate the total cost, means to plan according to the budget as well as empower the Mwisoko project staff through accountability approach.

\section{Acknowledgments}


ISSN 2250-3153

I wish to acknowledge Dr Kamande Mercyline for his contribution to this work from the beginning up to it's the completion. I also wish to extend my acknowledgement to the Mount Kenya University, Nyarugenge District authorities for their support and collaborative in term of data collection. 


\section{Reference}

Abdulkadir, H.S. (2014). Monitoring and Evaluation Johannesburg. World alliance for Citizen Participation.

Abdul-Rahman, H., Wang, C., \& Muhammad, N. A. B. (2011). Project Performance monitoring methods used in Malaysia and perspectives of introducing evaluation as a standard approach. Journal of Civil Engineering and management, 17(3), 445455.

Acevedo, G. L. (2010). Challenges in Monitoring and Evaluation: An opportunity to institutionalize M\&E systems. Working paper No.55853. Caribbean, Latin America.

Alhyari, S., Alazab, M., Venkatraman, S., Alazab, M \& Alazab, A. (2013). Performance evaluation of e-government services using balanced scorecard: An empirical study in Jordan", Benchmarking: An international Journal, 20(4) $512-536$

Asaka, C. N.,Aila, F. O., Odera, O., \& Abongo, B.E. (2012) projects selection and management implication in Kenyan local authorities. Asian Journal of Business and Management Sciences, 1 (10)65-75

Atencio, M. (2012). A critical success factors framework that includes leadership competencies for successful delivery of projects (Doctoral dissertation). University of Salford. Retrieved from Dissertation and Theses database. (http://usir.salford.ac.uk/30638/)

Banyenzaki, M. (2015). Contract Management practices and performance of the road construction projects: The case of Wakiso District, Unpublished dissertation in project Managements and Evaluation. Wakiso, Uganda.

Basha, Q. R. (2017). Sustainability issues in Civil Engineering: Methods and techniques (4 ${ }^{\text {th }}$ edition). Kansensero: Global Publishers Ltd.

Center for learning on Evaluation and Results (CLEAR). (2013). Demand and Supply: Monitoring, New York. USA.

Chapman A (2014). "Project management, tools, process, plans and project planning tips". Cambridge University Press

Cheruiyot, P.K., \& Kwasira, J. (2013). An assessment of devolving human resource function in Kenya: a case study of Nakuru country. International Journal of human resources management

City of Kigali, (2020). Annual report on urban electrification trial phase in Nyarugenge District. Kigali, Rwanda.

Cusworth, J. W., \& Franks, T.R (2013). Managing projects in developing countries. Routledge.

Florin, (2011). Developing an integrated Monitoring and Evaluation Flow for Sustainable Investment projects. Romania: The Bucharest Academy of Economic Studies.

Gaitano, S, (2011). The Design of M\&E Systems: A Case of East Africa Dairy Development project. A paper presented at INTRAC $7^{\text {th }}$ Monitoring and evaluation conference 2011

Gilbert, A. J, \& Ron, J. S. (2014). Sustainability in project Management competencies: Analyzing the competence Gap of project Managers. Journal of human resource and sustainability Studies, 2(4), 40-58.

Government of Rwanda. (2013). The Nation Census of the United Republic of Tanzania 2011/2012. Dar es Salaam: Tanzania bureau of statistics. Government. A report of road Maintenance Budget summary for road funds. Bangamoyo, Tanzania.

Hummelbrunner, R. (2010). Beyond log Frame: Critique, Variation and Alternatives, in Beyond log frame; Using systems Concepts in evaluation ', Tokio, FASID

Hwang, B. \& Lim, E. (2013). Critical Success Factors for key project players and Objectives; case Study of Singapore”. J. Const.Eng.Manage., 139(2), 204-215.

Ika, L A., Diallo, A., \& Thuillier, D. (2012).Critical success factors for World Bank projects: an empirical investigation. Internal Journal of project management, 30(1), 105-116.

Ika, 1. A. (2012). Project management for development in Africa: why projects are failing and what can be done about it. Project management Journal, 43(4), 27-41

Ika, L. A., Diallo, A., D. (2010). Project management in the international development industry: the project coordinator's perspective. International Journal of Managing projects in Business, 3(1), 61-93.

Khan E (2010).The next Generation of Economic Issues in Energy policy in Europe. London: CEPR Press.

Kule, J. W., \& Umugwaneza, A. (2016). The role of monitoring and Evaluation on project sustainability in Rwanda. Journal of business and social science. 5(7), 159-177.

Mackay, K. (2010). The nuts \& Bolts of M\&E Systems. Washington, D.C World Bank

Martinez, D. E. (2011). The logical framework Approach in Non-governmental organization. University of Alberta

Mauro, L. \& Marly, M (2014). Conceptual framework of sustainability in project management oriented to success. Sao Paulo: University of Sao Paulo.

Mbiti, M.V \& Kuruja, E. (2015). Role of monitoring and Evaluation on performance of Public Organization Projects in Kenya: A Case of Kenya Meat Commission M\&E on performance of Public Organization projects in Kenya. International journal of innovative Development and Policy studies, 3(3), 12-27.

Michael, B \& Eleanor, H. (2011). Monitoring and Evaluating urban development Programs. Washington, D.C.World Bank.

Ministry of Finance and Economic Planning (2013). Annual Reports on Small and Medium Enterprises development in Rwanda. Kigali. Rwanda.

Mladenovic, G., Vajdic, N., Wündsch, B., \& Salaje, A. T. (2013). Use of key performance indicators for PPP transport projects to meet stakeholders' performance objectives. Built environment project and Asset Management, 3(2), 228-249.

Myrick, D. (2013). A Logical framework for monitoring and Evaluation: A Pragmatic Approach to M\&E. Mediterranean Journal of social Sciences, 4(14), 423-42

Naidoo, I. A. (2011). The role of monitoring and evaluation in promoting good governance in South Africa: A case study of the department of social Development. Doctoral dissertation). University of Witwatersrand. 
ISSN 2250-3153

Ngogi, K., \& Nyandika. F. O. (2014). Influence of Stakeholders' Participation on Performance of Road Projects at Kenya National highways authority. Journal of Business Management, 1(11), 384-404.

Numutesi, E. (2018). The influence of Monitoring and Evaluation on project Performance: A Case of Africa Indoor Residual Spraying. A Research Project Submitted in Partial Fulfilment for the Award of a Degree in a Master of Business Administration (Project Management Option) of Mount Kenya University. Kigali, Rwanda.

Shah, N. (2013).Driving Project Success through Stakeholder Management. India: International Society for Pharmaceutical Engineering. 23(1), 311-325

Shimwa, P. (2019). Project implementation and project sustainability: a case s of electricity access rollout project, Nyarugenge, Rwanda. A Research Project Submitted in Partial Fulfillment for the Award of a Degree in Master of Business Administration (Project Management Option) of Mount Kenya University. Kigali, Rwanda.

World Bank, (2015).Improving Environmental Sustainability in Road Projects. Retrieved on 15/02/2017 from ww.worldbank.org. 